\title{
Primary Care Nurses' Perceptions and Experiences of Patients Being Overweight, as well as Visions and Attitudes About Working with Lifestyle Issues: A Qualitative Interview Study
}

\author{
Marie Bräutigam Ewe ( $\nabla$ marie.brautigam-ewe@regionhalland.se ) \\ Cathrine Hildingh \\ Hogskolan i Halmstad Sektionen for Halsa och Samhalle \\ Jörgen Månsson \\ Goteborgs universitet Sahlgrenska Akademin \\ Marie Lydell \\ Hogskolan i Halmstad Sektionen for Halsa och Samhalle
}

Goteborgs universitet Sahlgrenska Akademin https://orcid.org/0000-0002-5958-849X

\section{Research article}

Keywords: Lifestyle, Nurses' experiences, Overweight, Primary health care, Qualitative study

Posted Date: September 14th, 2020

DOI: https://doi.org/10.21203/rs.3.rs-48057/v1

License: (c) (i) This work is licensed under a Creative Commons Attribution 4.0 International License. Read Full License 


\section{Abstract}

Background: A primary health care centre (PHCC) is often the first point of contact for overweight patients, and nurses play key roles in overweight and lifestyle management. Since overweight is an increasing problem and a challenge for PHCCs to handle, it is important to describe primary care nurses' perceptions and experience with overweight problems, as well as their visions and attitudes regarding working with lifestyle issues.

Methods: This was a qualitative interview study. Thirteen nurses in PHCCs in the southwest of Sweden were interviewed with a semi-structured, face-to-face guide. The interviews were analysed using qualitative content analysis.

Results: The nurses had a wish and a willingness to work more with overweight and lifestyle issues than they currently did due to a lack of priority, resources, time and education. They experienced overweight as an increasing problem and felt that society should do more to stop its development. They considered that meeting with the patient was the most important task at PHCCs. How the conversations were structured without pointers and in an individualized manner was crucial for weight management to strengthen the patients' motivation to change. The nurses experienced that how to use and implement guidelines was unclear. They also asked for a national forum in Sweden for nurses working with overweight and lifestyle issues with lectures about the latest research in the area.

Conclusions: The nurses considered overweight to be a complex condition that requires a holistic approach with individualized care. To make this approach possible, a wider range of efforts should be offered to patients through more group meetings, lectures, and digital solutions. The development of a multidisciplinary team with different professions working with this patient group was the nurses' dream scenario. They wished for a preventive reception for pre-diabetic patients to save costs and suffering. Informing parents earlier about a healthy lifestyle at childcare centres in PHCCs and offering health examinations to promote preventive work were seen as good ideas. Implementing these suggestions in working with overweight and lifestyle issues could be a discussion among the management in PHCCs and for the decision makers in the region.

\section{Background}

In 2016, 39\% of the world's adults aged 18 years and over were overweight, and $13 \%$ were obese; obesity rates are expected to increase further until at least 2030 [1, 2]. In Sweden, 51\% of adults were overweight or obese in 2018 [3]. Overweight and obesity contribute to a large proportion of lifestyle-related diseases, such as diabetes type 2 and cardiovascular disease (CVD), and increase the burden on the health care system [4]. The obesity "pandemic" in almost all countries seems to be driven by changes in the food system, which is producing more processed, affordable food than ever before [5].

In low-income countries, obesity mostly affects middle-aged adults (especially women) from wealthy, urban environments, whereas in high-income countries, it affects both sexes and all ages but disproportionately affects disadvantaged groups to a greater extent [5].

The urban environment has many physical features that reduce the need for physical activity, such as elevators, escalators and other labour-saving devices, along with passive entertainment such as video games and TV watching [6]. This sedentary behaviour has caused what is called a sitting disease (defined as metabolic syndrome and other ill-effects) and is a greater threat to public health and mortality than smoking [7]; according to a large 
cohort study, maintaining physical activity from adolescence into later adulthood was associated with an up to $36 \%$ lower risk for all-cause mortality [8].

In the Ottawa Charter, health care was emphasized to be of particular importance as an arena for health promotion because of a range of contact with the overall population [9], but it seems to be difficult to reorient health care towards health promotion [10]. However, primary health care (PHC) is the first point of contact for all patients and is thus viewed as the ideal place to address obesity and lifestyle issues [11]. There are therapeutic recommendations regarding how to treat obesity in $\mathrm{PHC}[12,13]$; nevertheless, it seems challenging for health care professionals to face obesity; according to one study, they are experiencing this dilemma because the patient is recognized as central in disease management but is also unwilling to change, which is a major potential barrier to treatment [14].

In a Swedish study, 73\% of all health professionals in PHC would like to work more to support the promotion of healthy lifestyles among their patients, and nurses were most favourable towards this work [15]. Nurses in a primary health care centre (PHCC) have two key roles in obesity management. First, they work with overweight patients with comorbidities; second, they work with healthy overweight patients [16]. It seems that healthy overweight patients may require a stronger motivation for change and a discussion beyond future health risks, but all overweight patients also need clearer guidance tailored to their own particular circumstances to lose weight and consistent advice [16].

PHCCs follow the guidelines from the National Board of Health and Welfare for lifestyle counselling focusing on alcohol, smoking, unhealthy eating habits and inadequate physical activity for patients at risk (e.g., overweight, diabetes and high blood pressure) [17]. According to a two-year study of health care professionals about their use of practical guidelines, nurses were the professionals who had increased their lifestyle counseling most; however, there was room for improvement concerning methods for remedying alcohol consumption and unhealthy eating habits [15].

A comparison between Sweden and the US regarding patients' views of lifestyle counselling by their physician in a PHCC showed similar gaps between the patient's expectations for lifestyle counselling and primary care provider delivery [18]. Men in the US wanted more advice about eating habits than Swedish men, but US patients reported more frequent discussions of healthy lifestyle habits with their provider than Swedish patients [18].

Overweight is a sensitive topic, and patients who are overweight often experience stigmatization and discrimination [19]. It is also known that there could be a weight bias in the interaction between healthcare professionals and the patients [20]; therefore, it is important to create a climate with empathy and compassion where the patients feel seen and listened to [21]. A recommended method for lifestyle conversations is motivational interviewing (MI) [22]. The method seemed especially suitable for patients who have self-reported that they are motivated and aware of their role in making lifestyle changes. MI can enable patient self-determination and create a sense of well-being [23].

The main difficulty in the management of weight loss lies in its maintenance once it is achieved. One study showed that significantly more patients in a motivational group treatment achieved a reduction of $5 \%$ or more of the initial weight and improved cardiovascular risk factors compared to the control group [24].

However, there are obstacles to overcome to address obesity in PHCC. A review of studies about physician and nurses' approach to overweight and obese patients showed that health advice is more likely to be given when Body mass index BMI increases and can be of poor quality due to educational barriers and availability of resources [25, 26]. On the other hand, confidence in communication skills and the ability to create bonds between the nurse and 
the patient are important factors that facilitate approaching people suffering from obesity. These aspects require ongoing education for nurses and other practitioners about raising the topic with patients in a non-stigmatizing and non-harmful way $[27,28]$. Other difficulties and new challenges they may encounter include internet-informed patients who challenge the nurse's role [29].

Most nurses in PHC are receptive to and play a key role in health promotion work and are well suited to work with this patient group. It should be clarified how this work can be better organized for the future from the nurse's point of view to be able to slow down the development of obesity and metabolic diseases as well as improve public health.

\section{Aim}

To describe primary care nurses' perceptions and experience with overweight problems, as well as their visions and attitudes to working with lifestyle issues.

\section{Methods}

\section{Study design}

The study had a descriptive design with a qualitative method and an inductive approach. Semi-structured face-toface interviews were conducted with thirteen practice nurses in the southwest of Sweden.

\section{Participants}

The participants were nurses in a PHCC (registered nurses, health nurses or diabetic nurses). A strategic selection was used regarding age, work experience, gender and private or public workplace. Twelve of them were women aged 27-61 years, and one was a 62-year-old man; the median age was 51 years. Their working experience varied from 2-40 years with a median of 28 years. They were recruited from seven primary health care centres (PHCCs) located in the southwest of Sweden. Four of seven PHCCs had more patients with foreign backgrounds and lower socioeconomic situations than the other PHCCs. The number of patients listed at each PHCC varied from 500012500 persons. Each head manager of the PHCC received an e-mail with an information letter about the study, and they were asked if they were interested in participating in the study. They were also asked to forward the e-mail to those nurses who worked with lifestyle issues with a focus on overweight. A reminder was sent out after ten days if no one had responded. Thirty-five PHCCs in southwest of Sweden received an e-mail, and three of them declined because of lack of time. Three managers answered, but no nurses replied despite the reminder. In total, ten PHCCs agreed to participate. One PHCC participated with two nurses, and one participated with three nurses; the other eight participated with one nurse. Nineteen PHCCs did not answer at all. When the nurses agreed to participate, we conducted an appointment at their workplace. One nurse was interviewed in her home. They received both verbal and written information about the study and a consent form to read and sign when we met before the interview.

\section{Data collection}

Data were collected using an open qualitative interview [30] in the form of a dialogue.

The recruitment occurred between October 2019 and February 2020. A semi-structured interview guide developed by the authors was used with open questions, and the interviewer also had the opportunity to ask probing questions. The first interview was carried out as a pilot, and then included in the study. The topics were nurses' thoughts about 
overweight in general and in society, why overweight has increased, what experiences they had working with patients with overweight and lifestyle difficulties, how they worked with lifestyle issues and if overweight was prioritized in PHCCs. Furthermore, there were questions regarding if they received support from the manager, if there were ethical dilemmas, what results they obtained and if they had any dream scenarios of how they would like to work with obesity and lifestyle issues. The interviews lasted from 22 minutes to 45 minutes and were digitally recorded and transcribed verbatim. Notes was also taken during the interviews. Data saturation was applied when no new data occurred in the interviews.

\section{Data analysis}

Qualitative content analysis was conducted based on the steps described by Graneheim \& Lundman [31]. The analysis began by reading the written responses several times to obtain an overall sense of the data. Sentences and phrases corresponding to the aim of the study, referred to as meaning units, were highlighted. The meaning units were abstracted, coded and subsequently sorted into subcategories and categories based on similar content of the analysis; an example can be seen from table I (below). The subcategories and categories were discussed in a crossprofessional group with four people (two nurses, one physiotherapist and one physician). Throughout data analysis, several meetings of this cross-professional group occurred. All members in the group had read the interviews and discussed the codes, subcategories and categories until a consensus was met. The translation into the English language occurred after the data analysis.

Table 1

Example of the analytic process. Primary care nurses' perceptions of and experiences with overweight patients, as well as their visions and attitudes to working with lifestyle issues

\begin{tabular}{|c|c|c|c|c|}
\hline Meaning unit & $\begin{array}{l}\text { Condensed meaning } \\
\text { unit }\end{array}$ & Code & Subcategory & Category \\
\hline $\begin{array}{l}\text { It is important to talk in a good way so } \\
\text { that you do not offend the person in front } \\
\text { of you and encourage what is good; do } \\
\text { not to complain too much about what } \\
\text { does not work... do not use pointers } \\
\text { because it is very sensitive to discuss } \\
\text { overweight due to the psychological, } \\
\text { social and other implications. }\end{array}$ & $\begin{array}{l}\text { It is important to talk } \\
\text { so that you do not } \\
\text { offend the patient } \\
\text { and encourage what } \\
\text { is good and do not } \\
\text { use pointers. } \\
\text { Overweight is loaded } \\
\text { mentally and socially. }\end{array}$ & $\begin{array}{l}\text { encouraging } \\
\text { patient } \\
\text { meetings }\end{array}$ & $\begin{array}{l}\text { A good } \\
\text { patient } \\
\text { meeting } \\
\text { creates } \\
\text { conditions } \\
\text { for lifestyle } \\
\text { changes. }\end{array}$ & $\begin{array}{l}\text { Primary } \\
\text { care } \\
\text { nurses } \\
\text { wish to } \\
\text { promote } \\
\text { health } \\
\text { and } \\
\text { prevent } \\
\text { illness. }\end{array}$ \\
\hline
\end{tabular}

\section{Results}

Overweight was seen as a major problem, both economically and medically, as it creates diseases that we would not have suffered from to the same extent. The nurses felt that society could contribute more in slowing the development. They also described that the food industry and the supermarkets should make it easier for individuals to choose healthier food. Private actors outside PHCCs were also considered important in supporting people to a healthier lifestyle. PHCCs were perceived to be able to do more for those patients who needed help to lose weight and change their lifestyle, but more time, resources and individualized care were needed. The nurses described that individuals had their own responsibility to seek help if they could not manage it themselves.

The analysis of the interviews resulted in three categories: "Arenas for health promotion in society"; "Primary care nurses wish to promote health and prevent illness"; and "Support patients to take responsibility for their behaviour".

\section{Arenas for health promotion in society}


The nurses felt that society could contribute more to reducing overweight through various actors, such as through schools and different media, with efforts described in the sub-category "School's and media's impact on lifestyle". The subcategory "Regulation of the food market" was about how difficult it is to choose healthy food with the wide range available and that the producers and stores do not make it easier for the consumer to choose the right food. The individual is also exposed from all directions with a selection of fast food. The third subcategory "Health promotion outside PHCCs" describes that private actors are important arenas for influencing both eating habits and physical activity and are good for many people but not for everyone.

\section{School's and media's impact on lifestyle}

The nurses found it important to inform parents, children and teenagers early about what is a healthy lifestyle. School was considered an important platform, and the school nurse had a task to begin early when informing children and young people of what a healthy diet is in order to establish a normal eating behaviour. Schools should teach students to think critically about what to listen to and how to screen information from Instagram and Facebook. The nurses experienced that adolescents were adversely affected by images of a perfect body that led to eating disorders such as bulimia and anorexia. There was also experiences that the school should work more on encouraging more daily exercise and preferably encouraging gymnastics between lessons so that the students could develop a healthier lifestyle, prevent overweight and perform better in school. Information on healthy diets and exercise was considered important to disseminate. A nurse said the following:

"School is a place for information and thoughts on what is normal diet and exercise.... a little more wellness at school does not hurt." (Nurse 11)

The nurses felt that the media such as TV, magazines and social media had an increasing impact on our lifestyle and our eating habits and that different messages in newspapers and magazines about what is a healthy diet and lifestyle became confusing. They believed that it is not easy to choose the right one and know who to listen to. Stress and lack of time in everyday life made it even more difficult. Many times, the nurses took for granted that the patients knew more than they did about diet and exercise because of the supply of information on the internet, but sometimes they still had to provide more basic information. The influence of the media on our lifestyle, especially our eating habits, was something that was reflected around, and many felt that there was far too large a selection of different food programmes on TV with "delicious" food and far too few educational and informative programmes about what is a healthy diet and how to cook it. According to a nurse,

"All these food programmes on TV. It is senseless, everything is fixated on food. Television should show programmes about what a normal portion looks like instead of yummy food." (Nurse 3)

It was also perceived that advertising for sweets and fast food was occurring far too often and had a negative impact affecting everyone to crave unhealthy food and eat too much especially if they were already feeling bad and were more easily affected.

\section{Regulation of the food market}

Some of the nurses felt that actors such as the food industry and food stores made it difficult for individuals to know what a good and bad diet is. It is often the responsibility of the individual to resist sweets at the checkout. The nurses were told by several patients that it was a challenge to shop when they were hungry and stressed, and it was then difficult to resist unhealthy food. The availability of fast food and the fact that the stores were open around the 
clock were considered problems that made it difficult for individuals to make the right choices. A nurse pointed out the following:

"It is very easy to choose wrong because the food industry produces food with too much fat and sugar, and it becomes difficult to know what a healthy diet is without spending a lot of time on it." (Nurse 1)

The nurses described that the grocery stores should take greater responsibility and not put candy at the checkout because it became a major challenge for individuals to be attracted to wrong choices. Two groups that were particularly vulnerable were people with a foreign background and those with poor finances who often bought two large bottles of Coca Cola instead of one because it was marketed as being cheaper. The nurses expressed that society's government should do more to strengthen public health in school and promote outdoor environments and reduced consumption of sugar in the community to protect the most vulnerable groups. They described that society should raise the issue of introducing a sugar tax and lowering the price of healthy food. A nurse said the following: "A sugar tax would have been good, but then you should lower the price of healthy foods like fruits and vegetables." (Nurse 9)

Increased stress in the community was also experienced by nurses as a problem. People feel rushed; thus, cooking is not a priority; therefore, people buy fast food and use a car or escalator.

Another nurse described this as follows:

"It is a stressed society. Many people sleep poorly and have worries, anxiety.... then it is harder to eat, exercise and drink right. It is a challenging social situation." (Nurse 8)

\section{Health promotion outside of the health care mission}

The nurses agreed that private actors (outside PHCC) were needed to improve and maintain public health. For children and young people, "Generation Pep" was mentioned as those who work for children and young people's health who are also active in the school. The most common and popular actors for diet and exercise for adults were "Friskis and Svettis" and "Weight Watchers". Some nurses encouraged patients to help with the diet with the help of a Weight Watchers app where they could receive coaching and support every week that the nurses did not always have the opportunity to offer. The nurses' experienced that all patients were at different levels, and some were already using Weight Watchers or wanted to become members there; they thought that it was enough to follow up with them every six months. For others, this arrangement did not fit, but they wanted the nurse's support and to come and weigh at the PHCC. Some of the nurses described that it was important not only to talk but also to actively invite patients to training. One of the nurses had started a training group for the patients outside the PHCC at a training centre where the nurse used to go, and several patients accompanied her. A nurse said the following:

"I believe in not only talking but also showing. - You, on Wednesday we will see you at Friskis in the entrance. Then, you can get a try on a ticket. Over the years I have supported some 30 patients to develop a new lifestyle with exercise." (Nurse 13)

At a PHCC, a collaboration with Weight Watchers had been tried by the health centre by recruiting a number of patients who wanted to be part of a group, but the collaboration dissolved because there was some discussion about whether it was right or wrong. A nurse described it as follows:

"It was not that good. A public health centre that recruits clients to a private operator; what about all the other operators available then? I know there were discussions about this." (Nurse 7) 
In some areas with a poorer socioeconomic status, the nurses felt that a barrier to going to the gym and getting a personal trainer was that it was too expensive, and several times patients could not afford to purchase their medication; thus, it became a priority issue. One nurse expressed that there should be more trial offers for gym membership because the patients went to physiotherapy at the PHCC even though they were finished with the treatment but had to be discharged. Sometimes nurses felt that it would be good for some people to come out and meet others by training together. At one point, housing cooperatives had present at the PHCC and informed them that they had gyms and facilities for training and wanted them to distribute them to their patients who lived in those areas. The nurses described that some people managed to work out on their own with the help of various gym passes on TV or via the computer.

\section{Primary care nurses wish to promote health and prevent illness}

Primary care was considered to be an important actor to promote health and prevent overweight and unhealthy living habits caused by an unhealthy lifestyle. The nurses described that they came in contact with many people and had several opportunities to alleviate the problem and be able to inform and offer help even to those with low socioeconomics who could be difficult to reach otherwise. The first subcategory, "A good patient meeting creates conditions for lifestyle changes", was about the relationship between the patient and the nurse being important to succeed in a lifestyle change. In the "Lack of knowledge about how to use guidelines", the nurses described that it was difficult to know how to plan work on lifestyle changes according to guidelines, and it varied how to work between different PHCCs. "Ethical and cultural problems challenge the nurse's role" was about ethical dilemmas that the nurses faced in their work with obesity and lifestyle. In the fourth subcategory, "Tailored interventions as a meeting point for patients", the nurses described that they wanted to work more individually with more effort than before, preferably in teams around the patient, and to have the opportunity to meet the patients at an earlier stage before they had gone too far.

\section{A good patient meeting creates the conditions for lifestyle changes}

A good meeting with the patient was important for the nurses in building a relationship. It was perceived as a prerequisite for the patient to succeed with weight loss and a change in lifestyle. The nurses described that the care had changed; in ten years, the patient contact had decreased, and the administrative work increased. The nurses experienced that prevention work not was prioritized and that the money was saved here and now, but in the future, the nurses believed that it would be more expensive for PHCCs if the preventive and promotive work is not given more priority. According to a nurse,

"We must be allowed to have more nurse visits. We need to stop the development in the early stages. We cannot just cure the sick patients because we have to work more on this as well." (Nurse 12)

Several nurses also described that meeting with the patient and making them feel good was their most important job at the PHCC. How to talk to the patient was also considered important in order to avoid them and to do it as well as possible based on what the patients managed, wanted and understood was also important. Most nurses would have liked more time for this work because there was a lot to do, and the time available was sometimes not even enough for diabetic patients. The nurses described that there were requests from management to take the patients on shorter visits, but it was often not possible to do so during the first visit because there could be things that affected the patients' life situations such as divorce, work situations and childhood events. These experiences affect behaviour, and sometimes the nurses felt similar to conversational therapists. A nurse described it as follows: 
"The first visits need to be 60 minutes to go through everything; many may have a lifestyle that affects them. You are like a conversational therapist." (Nurse 2)

Being overweight was a sensitive subject and was experienced by all nurses, and it was important to build a relationship with the patients so that they felt seen; some needed more time to make the right contact and be motivated for a change, and it took a few visits. The nurses said that the manner of talking with the patients played an important role in bringing about a change. Since it was a delicate subject and they could feel violated, it was important not to use pointers. The nurses described that they used a variety of motivational conversations with open questions but did not always use the available technology to the full extent, and some wanted to have more education. Some nurses described that a challenge in the work was that at some PHCCs, the patients were sometimes very well prepared and educated. They had read on the internet and thought they knew what was good, and there was much discussion about different diets necessitating that the nurse balance the conversation. A nurse pointed out the following:

"There are many challenges. Here, many are well educated and do not want to listen to a nurse who tells them what to do and what not to do." (Nurse 7)

The nurses felt that adapting the efforts to each individual's life situation and conditions and gently taking care were important to achieve a sustainable result. A nurse said the following:

"When I am stressed and go too fast with dietary advice, then resistance comes from the patient, and I have to back track a little. The mood changes, and it's a dance all the time." (Nurse 8)

\section{Lack of knowledge how to implement guidelines}

Several nurses described that they educated themselves to become district nurses in order to do more preventive or promotive work, but it has not become as much as they wanted. The nurses described that they wanted to inform individuals as early as possible (child care centre), and parent groups were considered; maternal care was a good opportunity to decrease the development of overweight in society. They felt that there were guidelines for different conversational efforts during lifestyle conversations and for overweight, but it was unclear how to set it up; they felt that everyone worked differently on this. The nurses had the experience that at several PHCCs, there were no dietitians available, and they sometimes felt that for some more difficult patients they needed slightly more education about diet. A nurse pointed out the following:

"Having a dietician in this work would have been worth gold." (Nurse 12)

They expressed their desire for training in conversational methodology and psychology adapted to different personality types of patients in order to personalize and obtain better results. They felt that they had to read on their own and call colleagues around and ask each other. A nurse described it as follows:

"I would love to go on a diet education. So, you absorb everything and try to read a lot of yourself. You would have liked to go." (Nurse 2)

Another nurse described it as follows:

"What I miss very much is that there are no guidelines for health conversations in local health care, so we invent the wheel at all health centres. How to set it up, how many times, at what rate, etc. Everyone works differently." (Nurse 5) 
The diabetic nurses experienced that their work was easier than that of nurses because they had guidelines for diabetics to follow regarding how they would set up the health interviews. The patient materials used in the work were often the region's own materials, plate models and the Swedish Food Agency's advice.

\section{Ethical and cultural issues challenge the nurse's role}

The nurses described ethical difficulties and challenges that they had to deal with in their work with overweight and lifestyle. One nurse had preferably recommended another diet that she herself believed in and felt it was difficult for her not to talk about it. They experienced that there were many different diets and sources of dietary advice in circulation, but everyone agreed that it was important that the PHCC work be evidence based. The nurses experienced no major ethical problems, but there were challenges to work with overweight and lifestyle. The nurses described that PHCCs should be able to do more for those who needed it. The nurses felt that it could be a culture crash with foreign-born groups, especially for women from a culture where it was considered nice to be overweight and that it was associated with wealth. It was challenging for the nurses to manage them. Some described that it was unethical not to inform the patient because they needed to gain knowledge that being overweight is a health risk. A nurse said the following:

"I do not think you should be afraid to tell the patient that in order to get well in the knee you must lose weight before the surgery. Otherwise it is a waste of money and resources." (Nurse 11)

The nurses felt that it was easier to address the overweight problem if the patient already had high blood pressure because then you could go around the whole thing and start focusing on other factors such as sleep and stress to get into diet and overweight at a later stage. Of the lifestyle habits, alcohol consumption was considered to be the most difficult topic to talk about, but it also depended on what contact the nurses established with the patient. A nurse was worried that the patient would find it difficult that she was a normal weight and had no experience of being overweight; thus, she was careful to proceed cautiously. A nurse described it as follows:

"It is important to talk so that you do not offend the patient and encourage what is good and do not use pointers. Overweight is loaded mentally and socially." (Nurse 7)

Some nurses talked about the experience of meeting patients who should lose weight before an obesity surgery and who they met far later when they had lost weight but life had not become as they imagined. It was difficult to know how to support them. A nurse described what a patient told her regarding his thoughts about the situation:

"You have operated on my stomach, but you have done nothing to my mind and my brain." (Nurse 1)

The nurses described that the competence and awareness was high among staff working with lifestyle issues, and everyone felt it was important. Some nurses experienced some freedom in the work and felt that the manager did not go into detail about the work, but they still felt that it was not prioritized as they wished often due to staff shortages and having to put out "fires". A nurse said the following:

"My manager has an open window. Do as much as you can, but we must prioritize those who are sick." (Nurse 1)

\section{Tailored interventions as a meeting point for patients}

One nurse described that their PHCC had profiled itself as a healthy PHCC and wrote on its website that health is not something you can take for granted, but it takes a great deal of work to achieve good health. The nurses had varying wishes and visions on how to set up work with overweight and lifestyle to improve compliance and obtain 
better results. They felt that they had a good working relationship with the physiotherapists already, but most lacked a broader and more structured team collaboration with more professionals such as a psychologist and sometimes a dietician. The nurses expressed that the patients themselves could choose whether they wanted individual visits or group interventions. Preferably there would be a greater selection of efforts than previously to choose from. The nurses described that in most places, there were no overweight groups at present, but this was something that several nurses wanted to start. A nurse described it as follows:

"Teamwork among staff and groups is necessary if you have a dream. Then, patients can advise each other and motivate each other." (Nurse 12)

There was a desire for more time, support and resources for this work to be able to check on follow-up visits to a greater extent. The nurses wanted to provide effort earlier, especially for individuals with pre-diabetes to prevent the development of diabetes. A lifestyle reception with lectures as a meeting point for patients and a "preventive reception" that was more structured and focused on this were proposed. A nurse described it as follows:

"I would like a preventive reception where you could take them on closer visits, have motivational conversations and follow up more often. There is lots of money to save, as well as suffering, and we can help patients be happy." (Nurse 1)

The nurses described wanting to have availability during the evenings for a health school with tailor-made material with lectures for those who had difficulty coming during the day. A nurse told me that her PHCC intends to introduce video meetings to reach the patients and perhaps also to increase the availability of lifestyle calls. Another nurse would like to set up these services in her own way and start a cooking school where the patients can learn how to cook a healthy diet. Health examinations were described by some nurses as belonging to PHCCs and were thought to be a good way to prevent illness but were mostly offered at private PHCCs. The nurses thought that PHCCs should try to reach out to the population more with health information before overweight/obesity went too far. The nurses described that they also lacked a forum to meet and exchange similar experiences among diabetes nurses. They preferred to have lecturers, continuing education and information on the latest knowledge about obesity and lifestyle from reliable sources such as studies and reports from all over Sweden. A nurse pointed out the following:

"We have known that we need to know more about this. You want to feel safe in your profession so that you can talk to this patient about this; it needs to comes from safe sources, and you want not only the VG region but also nationally in Sweden to have more strength in what we say." (Nurse 11)

At some PHCCs, they worked more actively with prescriptions for physical activity on prescription (PaP) to the patients to get them started with training, and in some places, there was the possibility of referral to clinics that specialized in supporting people with physical activity at a low cost to the patient. Most nurses felt that it was a good tool that could be used more. At some clinics, it was more common for physiotherapists to prescribe PaP.

\section{Support patients to take responsibility for their behaviour}

The nurses described that they had a great commitment in supporting patients to develop a healthier lifestyle and achieve weight loss and that they liked the work, but it was also tiring. In the first subcategory, "The patient's motivation determines the outcome", the nurses described that how well the patients succeeded was usually due to how motivated they were; they felt that it was sometimes difficult to help patients find their motivation, and sometimes they had to give up. Several nurses also considered that patients' own responsibility for their health was 
important and influenced by various factors such as education, financial situation and mental health. This is described in subcategory number two, "The individual has to choose a healthy lifestyle".

\section{The patient's motivation determines the outcome}

The motivation of the patients varied depending on their life situations and played a major role in the results obtained. The nurses felt that it could be decisive for how well the patients succeeded in a lifestyle change. The nurses described that several patients lacked motivation and had not arrived voluntarily but at the doctor's advice. Some were more motivated when they had high blood pressure or diabetes, and others were not. The nurses found it difficult to know when to give up and when to continue the conversations. Motivating patients to change their lifestyles could be challenging, tiring, comfortless, heavy and difficult. As a nurse, you often experienced resistance from the patient to change and because the patient's motivation goes up and down; sometimes no one came anywhere, and it was not easy to know when to pause the visits. A nurse mentioned:

"It is difficult to penetrate all defence mechanisms when they are not motivated and yet give them time. It is a balance: when to give up and when to move on." (Nurse 5)

The nurses also experienced the work alternatively as fun, rewarding and enriching, especially when the patients had good results and felt better. Some patients had several poor living habits, and if they could get rid of at least one of them, they often felt much better, and then their motivation increased. The nurses found that getting patients to change their habits was difficult, but sometimes they succeeded. According to a nurse,

"One patient thanked me for beginning to understand that she needed to relax a bit and eat slowly and not eat while walking." (Nurse 3)

Another nurse said,

"This can be difficult to motivate. However, it is wonderful when you manage to get a person on the train, and they have succeeded in losing weight and started to move more. I can be a mainstay, but I can never be part of everyday life." (Nurse 9)

\section{The individual has to choose a healthy lifestyle}

The nurses described that as individuals, the patients had their own health responsibility, but that they have different presumptions depending on their education, economic situation, previous illnesses and mental health. The nurses felt that the efforts needed to be tailored according to where the individuals were and what their life situations looked like. They also described that we have become more sedentary in front of computers and that this begins early in childhood. The nurses felt that parents should take greater responsibility and not sit with their smart phones themselves. A nurse described it as follows:

"The parents have a responsibility in raising children; they drive the children everywhere, but they have to make sure that the children start to move more."(Nurse 5)

The nurses described that as a parent, one must be a good role model in terms of diet, exercise and social media and live as one learns. A nurse said,

"It is important to introduce your children and grandchildren early in training so that they develop habits for life." (Nurse 13) 
One problem that the nurses perceived was that there was much information available, and it could be difficult to screen for what is good or bad; they felt that PHC has a responsibility to work with evidence-based information and convey what is good. They also described that some patients had good knowledge and had tried a variety of diets and counted calories. Those patients could try different apps and write down what they ate or use pedometers, while others had to start with their meal plan as eating more than one meal of food a day. A nurse mentioned the following:

"For some, eating twice a day may be enough and just not one meal at 21:00, and for others, you can go in and look at different fats." (Nurse 2)

The nurses felt that the individual's choices were influenced by knowledge about good food, lack of time and stress. Socioeconomics and education also played major roles, and in some cases, foreign background leading to a lack of knowledge played a role; it was not uncommon to mix sugar in the milk for babies. Two nurses said,

"Cheap food is unhealthy, and patients lack knowledge on how to cook cheap and healthy food and think that everything should go fast." (Nurse 3)

"I try to get people to stop with fast food and buy ordinary food like meat, potatoes and vegetables and cook themselves. For those who say they ate dinner at McDonald's, I say it is no use because it is just "junk" you have eaten." (Nurse 13)

The nurses described that stress, such as being in a hurry when shopping and not being able to read the packaging or being hungry and buying things one should not, also affected what choices people make in everyday life. They also described that there was sometimes a lack of basic knowledge about why one was overweight and that it was possible to influence lifestyle change. The nurses perceived that the individual wanted to blame other things. They felt that the patients had their own responsibility for their choices. It could be easy, because of different circumstances, to act in a certain way, and the nurses felt that they had a mission to strengthen the patients to take responsibility for their lifestyles both in thought and action. They also expressed that the individual had a responsibility to seek help when the problems became too large and affected the quality of life. Two nurses described it as follows:

"The individual has the main responsibility to find out the facts about what is good and bad and react when he or she cannot do the things he or she wants because of being overweight. The individual has to react when he or she is cut off in his or her life and seek help." (Nurse 13)

"An important task is to get patients to focus on their lifestyle and not just their medication to feel good." (Nurse 12)

The nurses described that when patients felt that they were feeling better about their lifestyle change, it was easier for them to keep up and harder to go back to their old lives. Occasionally, the nurses found it difficult to exclude patients from the PHCC when they were supported with both diet and exercise to get started. A nurse described it as follows:

"Some patients want their own dietary advisor or PT for a long time, but health care is not for replacing the gym or a private dietary advisor. You have a personal responsibility as a patient."(Nurse 2)

The nurses found that those affected by mental illness had a harder time making a lifestyle change. It required more energy. The nurses saw people with mental health problems comforting themselves with sweets, getting a sugar

Page 13/20 
kick and then feeling a little better for the moment. They were experienced as difficult patients with major problems.

\section{Discussion}

The nurses in PHCCs expressed a positive attitude and a willingness to work with overweight and lifestyle issues, and they believed that PHCC is an ideal place to do so [27]; however, they experienced overweight as an increasing problem in all ages and felt that society should do more to stop its development. To make the environment less obesogenic, nurses recommended increasing the prices of unhealthy food and beverages. Similar to the World Health Organization (WHO), they identified a number of actions that the food industry could take to improve the population's nutrition by limiting the levels of fat, sugar and salt in products and practising responsible marketing [32]. Another subject the nurses brought up was the marketing of unhealthy food in all sorts of media; they thought that children and parents should be encouraged to develop their critical thinking about television food advertising and how it may influence social norms and dietary practices; this finding is in accordance with a previous study [33].

Nurses experienced that private actors in health promotion work, such as Weight Watchers, functioned well for some people but not for everyone often due to financial constraints. At one PHCC, they had tried to collaborate with Weight Watchers, but the relationship was discontinued because many of the staff felt it was unethical to favour an external actor; this was in contrast to a study in England where they collaborated and found better weight loss results with Weight Watchers than with the PHCC programme [34].

The nurses in PHCCs wanted to work more preventively than their work currently allows. Their work has changed over the years, and there is less time for the patient and more time for administrative work. There is a gap between the nurses' desire to work more with health promotion and prevention and the available resources, which also another study also pointed out [27]. The meeting with the patient was regarded as the most important task at the PHCC, and how the conversation was undertaken to create a nice atmosphere where the patient felt seen and listened to without use pointers was perceived as important [21] since overweight is a sensitive topic associated with stigma [19]. As in our study, it has been shown previously that nurses considered $\mathrm{Ml}$ as a good tool that is helpful and non-judgemental and puts nurses and patients on the same level, as well as promotes communication; however, sometimes because of a lack of knowledge, training and education, it was not fully used [35].

As in another study, the nurses experienced patients' motivation and willingness to change as a crucial but unresolved dilemma in the treatment of chronic conditions; however, information provision and enhancement of motivation were perceived to be at the core of healthcare professionals' duties [14]. Several nurses had limited education on the guidelines and how to use and implement them, and they believed that methods of working varied between different PHCCs. Although one study showed a certain improvement after two years regarding the use of guidelines, more improvements seem to be needed [15]. In our study, one way to discuss the problem from the nurses' point of view was to start a forum for those nurses who had worked with overweight and lifestyle issues nationally in Sweden where they could meet and exchange experiences and hear lectures and discuss research of the latest topics on the subject to improve their skills. According to the nurses, overweight and obesity are challenging health problems to manage, and mostly patients with chronic diseases require weight advice. For patients with overweight without comorbidities who were at risk, nurses reported broaching the subject indirectly, perhaps by asking the patient to be weighed during other activities such as during blood pressure readings or receiving blood tests [16]. The nurses also described some ethical dilemmas they encountered in their work with overweight individuals regarding their own weight status and attitudes. Another study also showed that nurses own weight status could be a potential barrier to raising the issue [28]. It is important for nurses to have this in mind, be

Page $14 / 20$ 
aware of the problem and not let it stop them from bringing the subject up. As in previous research [29], the nurses in our study experienced an increased number of internet-read patients, and this was a new challenge for them to handle these patients. They felt that their professional knowledge was being questioned, and sometimes the diets and other advice were not in line with the health care evidence-based advice. Otherwise, the nurses believed that not informing the patients about overweight being a health risk and the connection between overweight and developing various diseases was considered unethical economically and in terms of resources. Other issues occurred especially in women with foreign backgrounds and low socioeconomic status (SES) who fed their children and themselves unhealthy food and sweets [36]. They thought that being overweight was associated with wealth. It was difficult for the nurses to motivate them to lose weight, and it was a challenge not to use pointers. If PHCCs could develop more groups for overweight individuals, it may be an idea to suggest that these patients participate and receive inspiration from others. However, the nurses described their wish for more individualized care with a broader selection of different treatments for patient to chooses from, such as lectures about healthy diets, stress management and exercise sessions in groups or individualized meetings. Being overweight is a complex condition and is influenced by many different factors; in order to provide a holistic approach, it is necessary to involve other professional groups and build a multidisciplinary team around the patient [37].

The nurses also expressed that it was important to motivate and support patients to take their own responsibility for their lifestyle to succeed in weight reduction over time. To influence and support patients to do so requires individualized care and improved conversational skills for nurses. Sometimes professionals have unrealistic goals; even maintenance of the current weight can help to prevent disease and should therefore be interpreted as a success [14].

According to previous research [37], a health-promoting perspective leads to a shift from costs to human concerns, as well as a shift from focusing on problems and risk factors to seeing possibilities, resources and factors that keep people healthy. Apparently, there is still a way to go in health promotion work and obesity management.

\section{Strengths and limitations of the study}

To strengthen the credibility, the strategic selection provided a good geographical and socioeconomical distribution of the PHCCs, and the nurses were of different ages and all had different working experiences. They also had slightly different professions, and they had experience in working with overweight individuals. There was only one male nurse, but this reflects the reality in PHC. According to the transferability, the context is in PHCCs with several nurses working there. We used a strategic selection, and it was difficult to recruit participants for interviews. This reflects the situation for nurses in PHC who have a pressed schedule and perhaps a lack of interest in research. This may have resulted in nurses who were most interested in overweight and lifestyle issues being chosen to participate, and we did not reach those with another opinion; this could be a weakness. Otherwise, because the PHCCs were located in different socioeconomic areas, it reflected the nurses varied working situations and experiences. We had several open semi-structured questions to capture everything we wanted to identify and included probing questions. The fact that the shortest interview was not more than 22 minutes was due to the nurses' time limits in PHCCs. The nurses had tight schedules, and all of the interviews were performed at their workplaces, with one exception. According to transferability, we have chosen to present a table to follow the interpretation of the text with meaning units, condensed unit, codes, sub-categories and categories. The findings are illustrated by representative quotations in the text to help the reader to understand and assess the trustworthiness of the analysis. Nevertheless, we felt that the material was rich in content and answered the aim of the study. 
Qualitative content analysis [31] is an appropriate method when describing participants experiences. The purpose is broadly formulated. It is not just a phenomenon that we want to describe but a number of problem areas, and content analysis is a suitable method for this purpose. To achieve trustworthiness, such as credibility and dependability, the analysis was performed with help of all authors by reading the interviews and meeting several times to discuss further and reach a consensus. As in most qualitative studies, the researchers bring prior understanding because of their knowledge and previous experience with the subject. This can lead to both disadvantages and advantages when interpreting the results. Despite this, the researchers tried to stay as objective as possible in the interpretation. The data were collected for a fairly short period of time; therefore, there is no risk that it will change, and that strengthens the dependability.

\section{Conclusions}

The nurses experienced overweight in society as a major problem and felt that society should take greater responsibility to slow down its development through more health promotion in school and by influencing media channels to focus more on advertising on healthy food. They had an opinion that there should be stricter rules for food manufacturers and stores to produce healthier food and remove 'junk' food at the checkouts to make it easier for people to make the right choices. To improve public health, Parliament could lower the prices of fruit and vegetables, and perhaps a sugar tax could be another method.

The nurses described that guidelines for lifestyle habits were unclear in terms of how to use and implement them, and they wanted a more standardized line nationally in Sweden; there was also a perception that each PHCC worked differently. The nurses wanted to work more to prevent overweight than they currently were able to, and they wanted more time, resources and education about the latest research in the area and about conversation methods such as MI. They had visions of preventing the development of overweight at an earlier stage and informing patients about a healthy lifestyle before developing weight-related health issues by having a preventive reception with more frequent visits. Furthermore, nurses wanted to be able to offer individualized care with a wider range of lectures, groups and more digital care. Because obesity was perceived as a complex problem with sometimes ethical dilemmas, the nurses wanted to work in more structured teams around the patient with a psychologist, dietician and physiotherapist to offer better individualized care to patients and to achieved a more holistic approach.

The nurses had wishes and ideas about how to work more preventively against overweight and unhealthy living habits with patients to decrease the development of lifestyle-related diseases, but they did not have the power to influence the development of PHC management, which is governed by economics and political decisions. Continued research in the area could involve interviewing decision makers or managers in the regions about their strategies to make preventive work a higher priority in PHC.

\section{Abbreviations}

MI Motivational Interviewing

PHC Primary Health Care

PHCCs Primary Health Care Centres

\section{Declarations}




\section{Ethics approval and consent to participate}

The Central Ethical Review Board of the University of Stockholm granted permission for this study (no 29-2010).

Participants were informed about the aim of the study, their right to withdraw at any time without consequences and that the data would be stored and analysed confidentially and only be available to the researchers. When the participants agreed to participate, they were asked to sign a consent form.

\section{Consent for publication}

Not applicable

\section{Availability of data and materials}

The dataset generated during the study will not be shared due to participants' anonymity and confidentiality and to respect for the participants' sensitive contribution. The data are with the corresponding author but are available from the corresponding author on reasonable request.

\section{Competing interests}

The authors declare that they have no competing interests

\section{Funding}

This publication was funded by Sparbanksstiftelsen Varberg in 2017-06-30, which had no role in the design of the study or in writing the manuscript. Open access funding provided by Sparbanksstiftelsen Varberg and the PhD student was funded by Capio sjukvård $A B$ which had no role in the design of the study or in writing the manuscript.

\section{Authors' contributions}

All authors (MBE, JM, ML and $\mathrm{CH}$ ) contributed to planning of the study. MBE undertook the data collection, data analysis and drafting of the paper. All authors participated in the data analysis and in revising the paper. All authors read and approved the final manuscript.

\section{Acknowledgements}

We would like to thank the nurses for their participation in the study and Capio sjukvård AB for their financial support.

\section{Authors' information}

${ }^{1}$ Department of Public Health and Community Medicine/Primary Health Care, the Sahlgrenska Academy at the University of Gothenburg, Gothenburg, Sweden 
Marie Bräutigam Ewe \& Jörgen Månsson

${ }^{2}$ School of Health and Welfare, Halmstad University, Halmstad, Sweden

Marie Lydell \& Cathrine Hildingh

\section{References}

1. World Health Organisation. Obesity and overweight. Geneva: World Health Organisation; 2018.

2. Obesity Update OECD. Better policies and better lives. 2017. . Accessed 12 Dec 2019.

3. Folkhälsomyndigheten. Statens folkhälsoinstitut, folkhälsostatistik övervikt och fetma (Public Health Agency of Sweden, public health statistics overweight and obesity) 2018.

https://www.folkhalsomyndigheten.se/folkhalsorapportering-statistik/folkhalsans-utveckling/halsa/overviktoch-fetma/. Accessed 11 Dec 2019.

4. World Health Organization Regional Office for Europe. Prevention and control of noncommunicable diseases in the European Region: a progress report. 2013. http://www.euro.who.int/_data/assets/pdf_file/0004/235975/Prevention-and-control-of-noncommunicablediseases-in-the-European-Region-A-progress-report-Eng.pdf Accessed 15 Dec 2019.

5. Swinburn BA, Sacks G, Hall KD, McPherson K, Finegood DT, Moodie ML, et al. The global obesity pandemic: shaped by global drivers and local environments. Lancet. 2011;378:804-14.

6. Meldrum DR, Morris MA, Gambone JC. Obesity pandemic: causes, consequences, and solutions-but do we have the will? Fertil Steril. 2017;107:833-9.

7. Lee IM, Shiroma EJ, Lobelo F, Puska P, Blair SN, Katzmarzyk PT, et al. Effect of physical inactivity on major noncommunicable diseases worldwide: an analysis of burden of disease and life expectancy. Lancet. 2012;380:219-29.

8. Saint-Maurice PF, Coughlan D, Kelly SP, Keadle SK, Cook MB, Carlson SA, et al. Association of leisure-time physical activity across the adult life course with all-cause and cause-specific mortality. JAMA Netw Open. 2019;2:e190355.

9. World Health Organisation. The Ottawa charter for health promotion. Geneva: World Health Organisation; 1986.

10. Wise M, Nutbeam D. Enabling health systems transformation: what progress has been made in re-orienting health services? Promot Educ. 2007;14:23-7.

11. Campbell-Scherer D, Sharma AM. Improving obesity prevention and management in primary care in Canada. Curr Obes Rep. 2016;5:327-32.

12. Behandling för övervikt. Terapirekommendationer för i Halland Sverige (Treatment of Obesity. Therapy recommendations in the region of Halland Sweden) 2020.

https://terapirek.regionhalland.se/terapirekommendationer/kapitel16/behandling_av_obesitas/. Accessed 05 May 2020.

13. Regional Medicinsk Riktlinje. Fetma och övervikt-behandling i primärvården Västra Götalandsregionen, (Regional Medical Guideline. Obesity and obesity treatment in primary care Västra Götaland region) (20192021). 2020.

https://alfresco.vgregion.se/alfresco/service/vgr/storage/node/content/31216/Fetma\%20och\%20övervikt\%20\%20behandling\%20i\%20primärvården.pdf?a=false\&guest=true. Accessed 06 May 2020. 
14. Jallinoja P, Absetz P, Kuronen R, Nissinen A, Talja M, Uutela A, et al. The dilemma of patient responsibility for lifestyle change: perceptions among primary care physicians and nurses. Scand J Prim Health care. 2007;25:244-9.

15. Kardakis T, Jerdén L, Nyström ME, Weinehall L, Johansson H. Implementation of clinical practice guidelines on lifestyle interventions in Swedish primary healthcare - a two-year follow up. BMC Health Serv Res. 2018;18:227.

16. Phillips K, Wood F, Kinnersley P. Tackling obesity: the challenge of obesity management for practice nurses in primary care. Fam Pract. 2014;31:51-9.

17. Nationella riktlinjer för prevention och behandling vid ohälsosamma levnadsvanor. Socialstyrerlsen (National guidelines for prevention and treatment of unhealthy lifestyles) National Board of Health and Welfare) 2018. https://www.socialstyrelsen.se/regler-och-riktlinjer/nationella-riktlinjer/slutliga-riktlinjer/levnadsvanor/. Accessed 06 May 2020.

18. Jerdén L, Dalton J, Johansson H, Sorensen J, Jenkins P, Weinehall L. Lifestyle counseling in primary care in the United States and Sweden: a comparison of patients' expectations and experiences. Glob Health Action. 2018;11:1438238.

19. Deck KM, Haney B, Fitzpatrick CF, Phillips SJ, Tiso SM. Prescription for obesity: Eat less and move more. Is it really that simple? Open J Nurs. 2014;04:656-62.

20. Seymour J, Barnes JL, Schumacher J, Vollmer RL. A qualitative exploration of weight bias and quality of health care among health care professionals using hypothetical patient scenarios. Inquiry. 2018;55:46958018774171.

21. Bräutigam-Ewe M, Lydell M, Månsson J, Johansson G, Hildingh C. Dietary advice on prescription: experiences with a weight reduction programme. J Clin Nurs. 2017;26:795-804.

22. Miller WR, Rollnick S. Motivational interviewing: preparing people for change. New York: Guilford Press; 2002.

23. Brobeck E, Odencrants S, Bergh H, Hildingh C. Patients' experiences of lifestyle discussions based on motivational interviewing: a qualitative study. BMC Nurs. 2014;13:13.

24. Rodriguez-Cristobal JJ, Alonso-Villaverde C, Panisello JM, Travé-Mercade P, Rodriguez-Cortés F, Marsal JR, et al. Effectiveness of a motivational intervention on overweight/obese patients in the primary healthcare: a cluster randomized trial. BMC Fam Pract. 2017;18:74.

25. Kardakis T, Weinehall L, Jerdén L, Nyström ME, Johansson H. Lifestyle interventions in primary health care: professional and organizational challenges. Eur J Public Health. 2014;24:79-84.

26. Braga VAS, de Jesus MCP, Conz CA, Tavares RE, da Silva MH, Merighi MAB. Nursing interventions with people with obesity in primary health care: an integrative review. Rev Esc Enferm USP. 2018;51:e03293.

27. Walsh K, Grech C, Hill K. Health advice and education given to overweight patients by primary care doctors and nurses: a scoping literature review. Prev Med Rep. 2019;14:100812.

28. Blackburn M, Stathi A, Keogh E, Eccleston C. Raising the topic of weight in general practice: perspectives of GPs and primary care nurses. BMJ Open. 2015;5:e008546.

29. Sjöström AE, Hörnsten $\AA$, Hajdarevic S, Emmoth A, Isaksson U. Primary health care nurses' experiences of consultations with internet-informed patients: qualitative study. JMIR Nurs. 2019;2:e14194.

30. Polit DF, Beck CT. Essential of nursing research: appraising evidence for nursing practice. Philadelphia: Lippincott Williams and Wilkins; 2013.

31. Graneheim UH, Lundman B. Qualitative content analysis in nursing research: concepts, procedures and measures to achieve trustworthiness. Nurse Educ Today. 2004;24:105-12. 
32. World Health Organization. Global action plan for the prevention and control of non-communicable diseases 2013-2020. Geneva: World Health Organization; 2020.

33. Prell H, Palmblad E, Lissner L, Berg CM. Health discourse in Swedish television food advertising during children's peak viewing times. Appetite. 2011;56:607-16.

34. Ahern AL, Wheeler GM, Aveyard P, Boyland EJ, Halford JCG, Mander AP, et al. Extended and standard duration weight-loss programme referrals for adults in primary care (WRAP): a randomised controlled trial. Lancet. 2017;389:2214-25.

35. Östlund A-S, Wadensten B, Häggström E, Kristofferzon M-L. District nurses' and registered nurses' training in and use of motivational interviewing in primary care settings. J Clin Nurs. 2013;23:2284-94.

36. Hillier-Brown FC, Bambra CL, Cairns JM, Kasim A, Moore HJ, Summerbell CD. A systematic review of the effectiveness of individual, community and societal-level interventions at reducing socio-economic inequalities in obesity among adults. Int J Obes. 2014;38:1483-90.

37. Johansson $\mathrm{H}$, Weinehall L, Emmelin M. "If we only got a chance." Barriers to and possibilities for a more healthpromoting health service. J Multidiscip Healthc. 2009;3:1-9.

\section{Supplementary Files}

This is a list of supplementary files associated with this preprint. Click to download.

- COREQ32itemchecklistMBE200830.docx

- Artikel4interviewguide200830.docx 